\title{
Nuevas fronteras para la hormona antimülleriana
}

\author{
New frontiers for anti-mullerian hormone
}

\section{$\mathbf{L}$}

os conocimientos médicos, moleculares y de laboratorio cambian al tenor de las

nuevas ciencias médicas, investigativas e informáticas; estas últimas, crecientes en la clínica, la genómica y la proteómica, entre otras, son enriquecidas permanentemente por la introducción de términos y conceptos, pero, en especial, por la cualificación de funciones y señales. Bajo esta dialéctica del conocimiento se desarrollan nuevas tendencias en la biología celular, la epigenética y la hormonología.

Este potencial de conocimiento, moderadamente ignoto durante la vida antenatal, no es menos importante y cautivador, dado que cuenta con la influencia silenciosa de receptores, factores y la misma expresión tisular, so pena de que aún después del nacimiento una pequeña fracción del saber hormonal que acompaña al niño en su primera infancia permanezca camuflada por influencias ambientales, maternas o fisiológicas. Tras esta complejidad de acciones ha venido madurando el conocimiento de la hormona antimülleriana (AMH).

El concepto de la función hormonal - de todo nuestro interés-, que suele depender, entre otras, de acciones endocrinas, paracrinas y autocrinas, conforma una frontera del conocimiento que, en la mayoría de las veces, toma años por desarrollarse. En lo particular, desde la descripción de Alfred Jost en 1947, pasando luego por el gen SRY y el receptor de andrógenos, el papel de la hormona antimülleriana es ahora más amable, al verla como un trazador de la función testicular en la etapa fetal, la infancia y buena parte de la pubertad.

El conocimiento, y especialmente la etiología de un estado hipogonádico en los varones prepúberes es difícil de calificar desde el punto de vista funcional y, más aún, difícil de predecir antes de llegar a la edad merecedora de un Tanner de desarrollo genital 2 (testículos de $4 \mathrm{~mL}$ o más de volumen), a menos que se cuente con un defecto anatómico sugestivo de ello, un cariotipo compatible o una histología determinante. A estos antecedentes, que bien podemos calificar como específicos, se le suma el factor distractor con la pausa fisiológica del despertar puberal, ventana de silencio clínico y hormonal que todo individuo tiene por recorrer en sus primeros 8 a 10 años de vida.

No presumíamos que este desarrollo calificativo de los tejidos y las funciones estuviese matizado por acciones postremas de la hormona antimülleriana, diferentes a las ya establecidas de la regresión Mülleriana (permisiva a Wolff), desconociendo el camino conceptual de señalización que esta importante proteína traza en el desarrollo del varón y, en es- 
pecial, en el acompañamiento de la función testicular. Ahora podemos introducir nuevas herramientas, tanto de cribado como de detección del hipogonadismo primario del niño, desde el periodo neonatal y en la interfase de la pausa liberadora de gonadotropinas: se requirieron más de 50 años para posicionar una nueva y destacada función de la hormona antimülleriana diferente a la ya establecida desde el siglo pasado.

Invitamos al lector de este número de MEDICINA \& LABORATORIO a retomar el análisis de los hipogonadismos masculinos, esperando que, aunque muchos son primarios y referentes a un desorden anatómico, infeccioso o traumático, algunos otros dependen de mecanismos que, si bien estaban propositivamente pasando a un saber cotidiano y eufemísticamente "arcaico», ahora son renovados como sistemas, dado que cuentan con ubicación, señalización y genómica.

Por último, quisiera reconocerle a MEDICINA \& LABORATORIO su importante modelo de educación continua y, en particular, ser una excelente tribuna del sentir endocrinológico que nos motiva, desde sus páginas, ahora en sus manos, a darle la bienvenida a la nueva hormona antimülleriana.

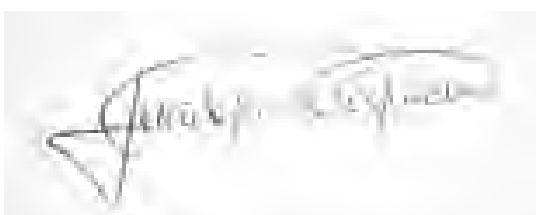

Juan M. Alfaro-Velásquez MD.

Endocrinólogo Pediátrico,

estudiante de Doctorado en Ciencias de la Salud, Universidad CES.

Medellín, Colombia, agosto 2017 